\title{
Assessment of serum interleukin 6 level in patients with chronic obstructive pulmonary disease: is it related to disease severity?
} Esmat A. Abd Elnaby ${ }^{a}$, Samah S. Abd Elnaiem ${ }^{a}$, Amira I. Mostafa ${ }^{a}$, Dina Sabry ${ }^{b}$, Alshaimaa Rezk I R Alnaggar ${ }^{c}$, Mohamed K. Haswa ${ }^{a}$

\begin{abstract}
Background Chronic obstructive pulmonary disease (COPD) is a common disease that can be prevented and even treated. It leads to high morbidity and mortality rates. Proinflammatory cytokines and oxidative radicals were found to be implicated in COPD pathogenesis.
\end{abstract}

Objectives To measure serum level of interleukin 6 (IL-6) in patients with stable COPD and also to detect the relationship of IL-6 levels with COPD severity.

Patients and methods A total of 50 patients having stable COPD, in addition to 20 healthy control individuals, were included in the study. History taking and clinical examination, BMI calculation, spirometry (postbronchodilator spirometry in COPD group), and 6-min walk test were done for all patients. Measurement of serum level of IL- 6 was done by using the enzyme-linked immunosorbent assay.

Results Serum level of IL- 6 showed significantly higher concentrations among patients with COPD compared with healthy individuals $[359.87 \pm 106.99$ and $188.92 \pm 77.97 \mathrm{pg} / \mathrm{ml}$, respectively; $P<0.001]$. An inverse nonsignificant correlation was found between serum level of IL-6 and 6-min walk test distance, forced expiratory volume in the $1 \mathrm{~s}$, forced vital capacity, and maximum expiratory flow $25-75 \%$ predicted

\section{Introduction}

Chronic obstructive pulmonary disease (COPD) is proved to be one of the diseases that lead to high morbidity and mortality rates [1]. It is also characterized by persistent inflammation complicated by irreversible airflow obstruction. This finally progresses to structural changes of the lungs [2]. COPD is now considered as a systemic inflammatory disorder associated with various extrapulmonary complications, like atherosclerosis, muscle wasting, weight loss, and cachexia [3].

Abundant inflammatory cells are found to be activated in patients with COPD and subsequent increase in the levels of pro-inflammatory cytokines and oxidative radicals, which are implicated in COPD pathogenesis [4]. Progressive parenchymal tissue destruction and remodeling of small airways are accompanied by excessive deposition of collagen especially collagen type-1 [5]. Recent studies revealed a relationship between collagen deposition and pro-inflammatory cytokines such as interleukin 6 (IL-6) and IL-8 [6].

On the contrary, some studies did not find close relationship between COPD and the known values. Mean IL-6 level was higher in the patients with severe and very severe COPD $(371.75 \pm 103.12 \mathrm{pg} / \mathrm{ml})$ compared with those with mild and moderate COPD $(336.82 \pm 113.72 \mathrm{pg} /$ $\mathrm{ml})(P=0.291)$.

Conclusion Serum level of IL-6 showed significant higher concentrations in patients with COPD when compared with control ones, but IL-6 level did not show significant correlation with the disease severity.

Egypt J Bronchol 2019 13:575-579

(C) 2020 Egyptian Journal of Bronchology

Egyptian Journal of Bronchology 2019 13:575-579

Keywords: chronic obstructive pulmonary disease, interleukin 6, inflammation

Departments of, ${ }^{a}$ Chest, ${ }^{\text {bBiochemistry, }}$ Internal Medicine, Faculty of Medicine, Cairo University, Cairo, Egypt

Correspondence to Amira I. Mostafa, MD, Department of Chest Diseases, Faculty of Medicine, Cairo University, Cairo, P.O. Box 11562, 11562, Egypt. Tel: 00201224977400;

e-mail: dramira755@gmail.com

Received: 5 June 2019 Accepted: 26 November 2019 Published: 21 January 2020

inflammatory markers like C-reactive proteins or tumor necrosis factors-alpha, proposing a controversy regarding the role of inflammation in COPD pathogenesis [7]. However, other studies reported that different inflammatory cells and different mediators might play a role in COPD progression, especially IL-6, which has become a subject of interest in research in the past years [8]. Moreover, many studies have proved that patients with COPD had higher IL-6 serum concentrations than healthy controls and is correlated with low spirometry values $[9,10]$.

IL-6 is mainly produced by T cells and macrophages. It is one of the ILs that works as a pro-inflammatory cytokine [11]. IL-6 was found to be elevated in exacerbation of COPD [12] and is found in the exhaled breath condensate and sputum during exacerbation and stability [13]. The presence of IL-6 in the airways of COPD is usually associated with

This is an open access journal, and articles are distributed under the terms of the Creative Commons Attribution-NonCommercial-ShareAlike 4.0 License, which allows others to remix, tweak, and build upon the work non-commercially, as long as appropriate credit is given and the new creations are licensed under the identical terms. 
sustained inflammation [14]. Some studies emphasized the association between IL-6 and poor clinical outcomes in patients with COPD [15]. However, the results have been always inconsistent and lacking adequate statistical power. Our study objective was to measure serum level of IL-6 in patients with stable COPD and to explore the relationship between IL-6 level and the COPD severity.

\section{Patients and methods}

A study, which was prospective, was carried out at the Chest Department of Kasr El-Ainy hospital, Cairo University, during the interval between April 2016 and December 2016. It was carried out on 70 male individuals, 50 patients with stable COPD and 20 healthy individuals. Human Ethical Committee of Cairo University approved the study, and an informed consent was given by all participants.

COPD was diagnosed on basis of the clinical history, physical examination, and performing spirometry with measurement of postbronchodilator parameters, especially forced expiratory volume in the $1 \mathrm{~s} /$ forced vital capacity (FEV1/FVC); if it is less than 0.70 , this establishes the presence of sustained airflow limitation according to the Global Initiative for Chronic Obstructive Lung Disease (GOLD 2016) [16].

Patients with history of exacerbations in the last month preceding the study, congestive heart failure or ischemic heart disease, neurological diseases, renal failure, or hepatic failure were excluded from the study.

Smoking history was emphasized, and dyspnea grade was assessed by modified Medical Research Council score. Laboratory investigations included complete blood count, serum sodium, serum potassium, liver functions, kidney functions, and blood sugar. BMI calculation was done as follows: weight $/$ height $^{2}$. Sixmin walk test (6MWT) was performed with measurement of 6MWT distance. Oxygen saturation and heart rate data were obtained (before and after $6 \mathrm{MWT}$ ) by using pulse oximetry.

COPD severity grading was done by spirometry. Measurement of the following parameters was done: FEV1\%, FVC\%, FEV1/FVC\%, and maximum expiratory flow 25-75\% (MEF25-75\%) predicted values were done for both groups. Only for COPD cases, the results of postbronchodilator were taken.

COPD grading and severity were done according to the following: mild GOLD 1, which shows FEV1 more than or equal to $80 \%$ predicted, moderate; GOLD 2, with measurement of $50 \%$ more than or equal to FEV1 less than $80 \%$ predicted, severe; GOLD 3 , with measurement of $30 \%$ more than or equal to FEV1 less than $50 \%$ predicted, and lastly very severe GOLD 4, with FEV1 less than 30\% predicted [16].

Serum level measurement of IL-6 was done using enzyme-linked immunosorbent assay kit provided by Invitrogen Corporation (Camarillo, California, USA) according to the instructions of the manufacturer.

\section{Statistical analysis}

Sample size estimation was performed using Power and Sample size (PS) program.

Data were analyzed using the statistical package Statistical Package for the Social Sciences, version 24 (IBM Corp. Released 2016. IBM SPSS statistics for Windows, version 24.0, Armonk, NY, USA:IBM Corp.). Mean, SD, median, and minimum and maximum were used for quantitative data, whereas the frequency (count) and relative frequency (percentage) for categorical data. Comparisons between quantitative variables were done using the nonparametric Kruskal-Wallis and Mann-Whitney tests [17].

$\chi^{2}$ test was used for comparing categorical data. When the expected frequency is less than 5 , we use exact test instead [18].

Spearman correlation coefficient was used for correlation between quantitative variables. The value was judged as statistically significant when $P$ value less than 0.05 [19].

\section{Results}

\section{Characteristics of the patients}

In total, 50 patients having stable COPD and 20 healthy controls were enrolled in the study. The demographic data and the clinical parameters are demonstrated in Table 1.

Table 1 showed that all patients with COPD and the healthy control ones were males. Their age ranged between 40 and 76 years for patients with COPD, with a mean of $57.18 \pm 9.03$ years. The normal individuals have age ranged between 46 and 60 years, with a mean of $53.10 \pm 4.61$ years. All healthy controls were nonsmokers. There was no statistically significant difference between patients with COPD and normal individuals in the BMI. 
There was a significant difference between patients with COPD and the normal individuals regarding 6MWT distance and oxygen saturation $(P<0.001)$.

\section{Results of spirometry and interleukin 6}

All the data of spirometry, including $\mathrm{FEV} 1 / \mathrm{FVC} \%$, FEV1\%, FVC\%, and MEF25-75\% predicted values,

Table 1 The demographic and clinical parameters of the patients with chronic obstructive pulmonary disease and the control group

\begin{tabular}{lccc}
\hline & Cases $(\mathrm{N}=50)$ & Control $(\mathrm{N}=20)$ & $\begin{array}{c}P \\
\text { value }\end{array}$ \\
\hline Age (years) & $57.18(9.03)$ & $54.10(4.61)$ & 0.07 \\
& {$[58(40-76)]$} & {$[53(46-60)]$} & \\
Smoking index & $40.88(24.65)$ & 0.00 & $<\mathbf{0 . 0 0 1}$ \\
(pack/year) & {$[35(8-150)]$} & & \\
BMI (weight/ & $25.97(5.06)$ & $27.40(3.91)$ & 0.221 \\
height $\left.^{2}\right)$ & {$[26(16-39)]$} & {$[27.50(19-35)]$} & \\
Dyspnea grade & $2.46(0.50)$ & 0.00 & $<\mathbf{0 . 0 0 1}$ \\
by m-MRC & {$[2(2-3)]$} & & \\
Distance of & $296.00(65.47)$ & $492.75(26.33)$ & $<\mathbf{0 . 0 0 1}$ \\
6MWT (m) & {$[300(150-420)]$} & {$[495(450-540)]$} & \\
$\mathrm{SO}_{2}$ (before & $95.04(4.48)$ & $98.00(0.79)$ & $<\mathbf{0 . 0 0 1}$ \\
6MWT) (\%) & {$[96(72-98)]$} & {$[98[(97-99)]$} & \\
SO ${ }_{2}$ (after & $93.02(6.74)$ & $97(0.86)$ & $<\mathbf{0 . 0 0 1}$ \\
6MWT) (\%) & {$[95.5(63-98)]$} & {$[97[(96-99)]$} & \\
Heart rate & $87.58(12.63)$ & $80(6.36)$ & $\mathbf{0 . 0 1 1}$ \\
(basal) (bpm) & {$[88.5(64-115)]$} & {$[81[(69-90)]$} & \\
Heart rate (after & $104.74(14.36)$ & $100.25(7.43)$ & 0.114 \\
6MWT) (bpm) & {$[106.5(74-135)]$} & {$[101[(88-115)]$} & \\
\hline
\end{tabular}

Data were expressed as mean (SD) and [median

(minimum-maximum)]. m-MRC, modified Medical Research Council of dyspnea; $6 \mathrm{MWT}$, 6-min walk test; $\mathrm{SO}_{2}$, oxygen saturation. Significant $P$ value less than 0.05 . The bold represents the significant $P$-value. were higher significantly among patients with COPD when compared with the healthy ones $(P<0.001)$. In addition, serum IL-6 levels were found to be significantly higher in the patients with COPD when compared with normal individuals $(188.92 \pm 77.97 \mathrm{pg} / \mathrm{ml} ; P<0.001)$, as it is shown in Fig. 1 and Table 2.

The serum levels of IL-6 were higher significantly in patients with COPD when compared with the healthy controls (Fig. 1).

Patients with COPD were subdivided according to disease severity into mild (two patients, 4\%), moderate

Table 2 Spirometric data and serum interleukin 6 level among patients with chronic obstructive pulmonary disease and the control group

\begin{tabular}{lccc}
\hline Spirometry & Cases $(N=50)$ & Control $(N=20)$ & $\begin{array}{c}P \\
\text { value }\end{array}$ \\
\hline FEV1/FVC\% & $56.72(8.09)$ & $82.30(4.86)$ & $<0.001$ \\
& {$[57.5(38-68)]$} & {$[83(74-92)]$} & \\
FEV1\% & $43.96(18.94)$ & $81.00(5.91)$ & $<0.001$ \\
predicted & {$[37.5(14-85)$} & {$[81.5(70-89)]$} & \\
FVC\% & $58.88(23.19)$ & $94.05(5.41)$ & $<0.001$ \\
predicted & {$[57.5(18-111)]$} & {$[95.5(84-101)]$} & \\
MEF25-75\% & $24.94(13.39)$ & $70.15(6.89)$ & $<0.001$ \\
predicted & {$[21.5(7-57)]$} & {$[69(60-80)]$} & \\
Interleukin 6 & $359.87(106.99)$ & $188.92(77.97)$ & $<0.001$ \\
level (pg/ml) & {$[335.5(160-574)]$} & {$[160.2$} & \\
& & $(95-320)]$ & \\
\hline
\end{tabular}

Data were expressed as mean (SD) and [median

(minimum-maximum)]. FEV1, forced expiratory volume in the $1 \mathrm{~s}$; FVC, forced vital capacity; MEF, maximum expiratory flow.

Significant $P$ value less than 0.05

Figure 1

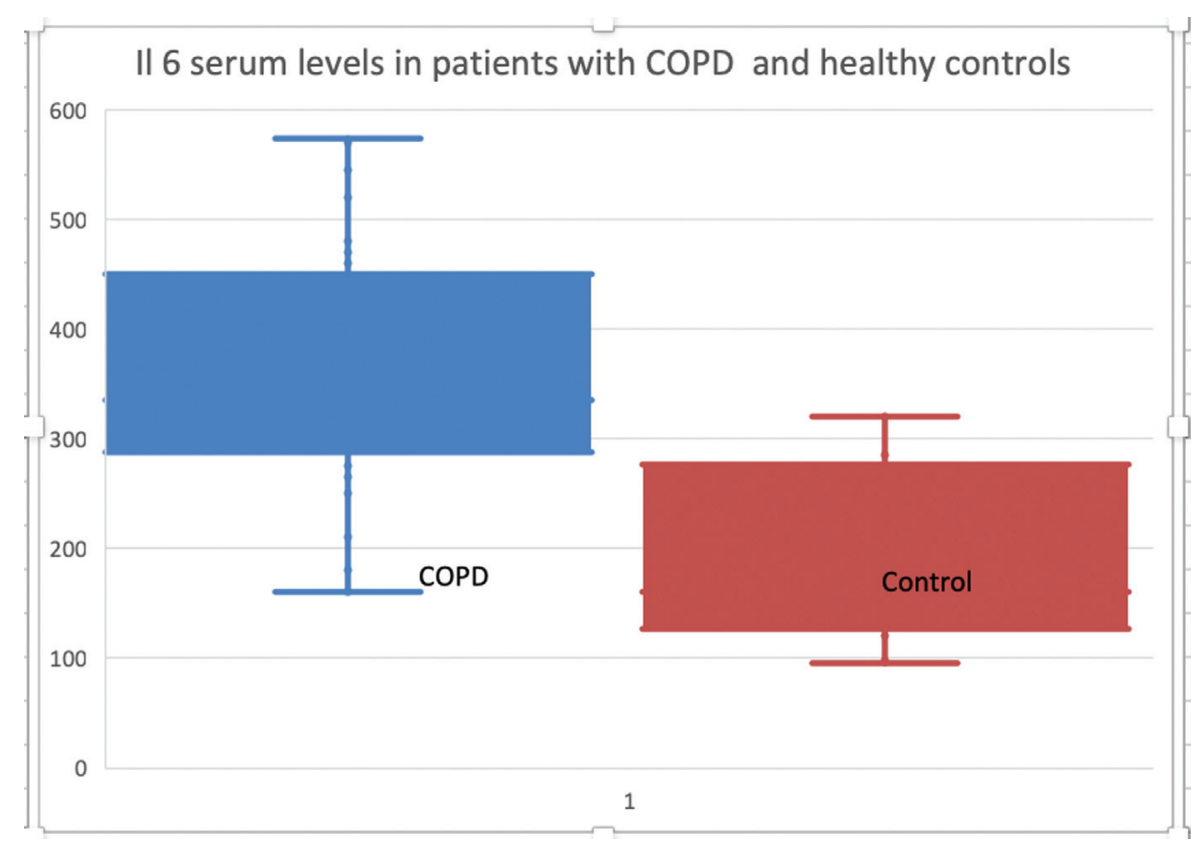

Serum levels of IL-6 were significantly higher in patients with COPD compared with healthy controls. COPD, chronic obstructive pulmonary disease; IL-6, interleukin 6. 
Table 3 Correlation between serum level of interleukin 6 and the 6-min walk test and the spirometric parameters in the chronic obstructive pulmonary disease group

\begin{tabular}{lcc}
\hline & $\begin{array}{c}\text { Correlation } \\
\text { coefficient }\end{array}$ & $\begin{array}{c}P \\
\text { value }\end{array}$ \\
\hline Distance of 6MWT (m) & -0.065 & 0.653 \\
$\mathrm{SO}_{2}$ before 6MWT (\%) & 0.121 & 0.401 \\
$\mathrm{SO}_{2}$ after 6MWT (\%) & 0.040 & 0.783 \\
Basal heart rate (bpm) & 0.066 & 0.648 \\
Heart rate at the end of 6MWT & -0.017 & 0.905 \\
(bpm) & & \\
FEV1/FVC\% & 0.079 & 0.587 \\
FEV1\% predicted & -0.142 & 0.326 \\
FVC\% predicted & -0.141 & 0.329 \\
MEF25-75\% predicted & -0.264 & 0.064 \\
\hline
\end{tabular}

6MWT, 6-min walk test; FEV1, forced expiratory volume in the $1 \mathrm{~s}$; FVC, forced vital capacity; MEF, maximum expiratory flow; $\mathrm{SO}_{2}$ oxygen saturation. Significant $P$ value less than 0.05

(15 patients, $30 \%$ ), severe (20 patients, $40 \%$ ), and very severe (13 patients, 26\%). There was no significant difference between IL-6 serum level of patients with mild and moderate COPD versus those with severe and very severe COPD; however, mean value of IL-6 in the severe and very severe group was actually more than in the mild and moderate group $(371.75 \pm 103.12$ versus $336.82 \pm 113.72 \mathrm{pg} / \mathrm{ml} ; P=0.2$ ).

\section{Correlation of interleukin 6 and different clinical and spirometric parameters}

There was no significant correlation between serum level of IL- 6 and any one of the clinical parameters, including age, smoking index, BMI, and dyspnea grade. Moreover, there was no significant correlation between IL-6 level and 6MWT distance, oxygen saturation, and heart rate data. An inverse correlation was found between IL-6 level and FEV1\%, FVC\%, and MEF25-75\% predicted values, although no statistical significance was detected (Table 3).

\section{Discussion}

Different studies highlighted the important role of IL6 as an inflammatory marker in COPD, as presented by the meta-analysis and systematic review done by Wei et al. [20] of a total 33 studies, which concluded that the serum levels of IL-6 were higher in patients with stable COPD than healthy control ones.

In this study, we concluded that serum level of IL-6 in patients with COPD was approximately double the value found in the control individuals, which agrees with E1-Shimy et al. [21], who proved that the circulating serum IL-6 concentrations were higher significantly in patients with COPD in comparison with the control individuals.
Moreover, our study goes hand in hand with de Moraes et al. [22] and Kolsum et al. [23] who also found that the patients with COPD exhibited significantly elevated serum levels of IL-6 compared with that of the control group, which suggests that there is systemic inflammatory activity in patients with stable COPD.In the current study, it was found that there was no significant correlation between serum level of IL-6 and the clinical parameters, including age, smoking index, BMI, and dyspnea degree by modified Medical Research Council. There was a nonsignificant inverse correlation between serum level of IL-6 and 6MWT distance. de Moraes et al. [22] also found that there was no difference in the serum concentration level of IL-6 and IL-8 when they divided the groups into divisions according to the distance covered.

Regarding relationship between serum IL-6 and spirometry findings, our study demonstrated that there was a nonsignificant negative correlation between IL-6 serum level and FEV1\%, FVC\%, and MEF25-75\% predicted values. However, Soler et al. [24], Samy et al. [25], and Attaran et al. [26] found a negative significant correlation between IL-6 levels and FEV1\%. These differences may be attributed to the limited number of the patients in our study.

\section{Conclusion}

It could be concluded that serum level of IL-6 was significantly higher among patients having stable COPD when compared with the controls, but IL-6 level did not show significant correlation with the disease severity as assessed by FEV1\% predicted.

\section{Financial support and sponsorship \\ Nil.}

\section{Conflicts of interest}

There are no conflicts of interest.

\section{References}

1 Wang C, Xu J, Yang L, Xu Y, Zhang X, Bai C, et al. Prevalence and risk factors of chronic obstructive pulmonary disease in China (the China Pulmonary Health $[\mathrm{CPH}]$ study): a national cross-sectional study. Lancet 2018; 391:1706-1717.

2 Balkissoon R, Lommatzsch S, Carolan B, Make B. Chronic obstructive pulmonary disease: a concise review. Med Clin 2011; 95:1125-1141.

3 Hillas G, Perlikos F, Tsiligianni I, Tzanakis N. Managing comorbidities in COPD. Int J Chron Obstruct Pulmon Dis 2015; 10:95.

4 Mannino DM, Ford ES, Redd SC. Obstructive and restrictive lung disease and markers of inflammation: data from the Third National Health and Nutrition Examination. Am J Med 2003; 114:758-762.

5 Jones RL, Noble PB, Elliot JG, James AL. Airway remodelling in COPD: it's not asthma!. Respirology 2016; 21:1347-1356. 
6 Zeng YY, Hu WP, Zuo YH, Wang XR, Zhang J. Altered serum levels of type I collagen turnover indicators accompanied by IL-6 and IL-8 release in stable COPD. Int J Chron Obstruct Pulmon Dis 2019; 14:163.

7 Franciosi LG, Page CP, Celli BR, Cazzola M, Walker MJ, Danhof M, et al Markers of disease severity in chronic obstructive pulmonary disease. Pulm Pharmacol Ther 2006; 19:189-199.

8 Garcia-Rio F, Miravitlles M, Soriano JB, Muñoz L, Duran-Tauleria E, Sánchez G, et al. Systemic inflammation in chronic obstructive pulmonary disease: a population-based study. Respir Res 2012; 11:1-15.

9 Wedzicha JA, Seemungal TAR, MacCallum PK, Paul EA, Donaldson GC Bhowmik A, et al. Acute exacerbations of chronic obstructive pulmonary disease are accompanied by elevations of plasma fibrinogen and serum IL-6 levels. Thromb Haemost 2000; 84:210-215.

10 Ancochea J, Badiola C, Duran-Tauleria E, Río FG, Miravitlles M, Muñoz L, et al. The EPI-SCAN survey to assess the prevalence of chronic obstructive pulmonary disease in Spanish 40-to-80-year-olds: protocol summary. Arch Bronconeumol (English Ed) 2009; 45:41-47.

11 Pinto-Plata V, Casanova C, Müllerova H, de Torres JP, Corado H, Varo N, et al. Inflammatory and repair serum biomarker pattern. Association to clinical outcomes in COPD. Respir Res [Internet] 2012; 13:71.

12 Akbulut HH, Ozden M, Deveci F, Muz MH. IL-6 and IL-8 levels in patients with acute exacerbation of chronic obstructive pulmonary disease. J Clin Diagn Res 2009; 3:1285-1288.

13 Agusti AGN, Noguera A, Sauleda J, Sala E, Pons J, Busquets X. Systemic effects of chronic obstructive pulmonary disease. Eur Respir J 2003; 21:347-360.

14 Rincon M, Irvin CG. Role of IL-6 in asthma and other inflammatory pulmonary diseases. Int J Biol Sci 2012; 8:1281-1290.

15 Agustí A, Edwards LD, Rennard SI, MacNee W, Tal-Singer R, Miller BE, et al. Persistent systemic inflammation is associated with poor clinical outcomes in COPD: a novel phenotype. PLoS One 2012; 7:e37483.
16 Global Initiative for Chronic Obstructive Lung Disease (GOLD). Global strategy for the diagnosis, management and prevention of COPD. Global Initiative for Chronic Obstructive Lung Disease. 2016.

17 Chan YH. Biostatistics102: quantitative data - parametric \& nonparametric tests. Singapore Med J 2003a; 44:391-396.

18 Chan YH. Biostatistics 103: qualitative data -tests of independence. Singapore Med J 2003b; 44:498-503.

19 Chan YH. Biostatistics 104: correlational analysis. Singapore Med J 2003c; 44:614-619.

20 Wei J, Xiong X, Lin Y, Zheng B, Cheng D. Association between serum interleukin- 6 concentrations and chronic obstructive pulmonary disease: a systematic review and meta-analysis. Peer J 2015; 3:e1199.

21 El-Shimy WS, El-Dib AS, Nagy HM, Sabry W. A study of IL-6, IL-8, and TNF- $\alpha$ as inflammatory markers in COPD patients. Egypt J Bronchol 2014; 8:91.

22 de Moraes MR, da Costa AC, de Sousa Corrêa K, Junqueira-Kipnis AP, Rabahi MF. Interleukin-6 and interleukin-8 blood levels' poor association with the severity and clinical profile of ex-smokers with COPD. Int J Chron Obstruct Pulmon Dis 2014; 9:735.

23 Kolsum U, Roy K, Starkey C, Borrill Z, Truman N, Vestbo J, et al. The repeatability of interleukin-6, tumor necrosis factor- $\alpha$, and C-reactive protein in COPD patients over one year. Int $J$ Chron Obstruct Pulmon Dis 2009; 4:149.

24 Soler N, Ewig S, Torres A, Filella X, Gonzalez J, Zaubet A. Airway inflammation and bronchial microbial patterns in patients with stable chronic obstructive pulmonary disease. Eur Respir J 1999; 14:1015-1022.

25 Samy N, El-Maksoud A, Khayyal AE, Imam A. Clinical utility of biomarkers as predictors of lung function in chronic obstructive pulmonary disease. NY Sci J 2010; 3:25-32.

26 Attaran D, Lari SM, Towhidi M, Marallu HG, Ayatollahi H, Khajehdaluee M, et al. Interleukin-6 and airflow limitation in chemical warfare patients with chronic obstructive pulmonary disease. Int $\mathrm{J}$ Chron Obstruct Pulmon Dis 2010; 5:335. 